\title{
TEMPORAL- SPATIAL CHANGES IN AEROSOLS DURING WINTER HAZE OF WUHAN: A TYPICAL HIGH-HUMID INLAND CITY IN CENTRAL CHINA
}

\author{
Shikuan Jin ${ }^{1}$, Yingying Ma ${ }^{1, *}$, Wei Gong ${ }^{1}$, Ming Zhang ${ }^{2}$
${ }^{1}$ State Key Laboratory of Information Engineering in Surveying, Mapping and Remote Sensing, Wuhan University, Wuhan, Hubei Province 430079, China - yym863@whu.edu.cn
${ }^{2}$ Hubei Key Laboratory of Critical Zone Evolution, School of Geography and Information Engineering, China University of \\ Geosciences, Wuhan 430074, China
}

Commission III, WG III/8

KEY WORDS: Aerosols Optical Properties, Hygroscopic Growth, Haze, High-Humid Urban Condition

\section{ABSTRACT:}

Temporal and spatial changes of aerosols characteristics was investigated to improve understandings of haze in winters of Wuhan, based on measurements of a CIMEL sun-sky radiometer and a modified Dark Target (DT) method. A large increase in no-absorbing and fine-mode particle is the main characteristic of aerosol during winter haze periods. From no-haze to haze conditions, aerosol optical depth (AOD), fine-mode peak value of size distribution, and single scattering albedo increased respectively from $0.46,0.47$ $\mu \mathrm{m}^{3} / \mu \mathrm{m}^{2}$, and 0.84 to $0.93,0.91 \mu \mathrm{m}^{3} / \mu \mathrm{m}^{2}$, and 0.87 . Based on above aerosol optical and microphysical properties, we re-calculated aerosol models and improved the DT method. Results showed that our improvement increased the expect error (\%) from 17.9 to 70.9. Spatial distributions revealed that heavy aerosol loading often occurred in rural and suburban areas rather than city centre. With the haze developing, the AOD increased by $\sim 0.3$ over north of Wuhan and showed a downward trend from north to south.

\section{INTRODUCTION}

As an important component of the atmosphere, atmospheric aerosols have significant impacts on the earth's radiative budget balance, the hydrological cycle, and the global climate change (Charlson et al., 1992; Nakajima et al., 2007; Zhang et al., 2018). In recent years, an increase in anthropogenic aerosol emissions has been confirmed and received increasing attention due to worldwide industrial and economic development. Especially in the East-Central China, a large number of anthropogenic aerosols have increased the atmospheric aerosol loading, changed the primordial aerosol properties, and caused an increasing number of air pollution problems (Tao et al., 2012; Liu et al., 2020). Haze has posed a threat to People's Daily activities and health.

Haze is an extreme disaster weather phenomenon, caused by the increase in anthropogenic aerosol emissions from human activities, and in turn harmful to human. There have had a number of studies at different space-time scale in order to investigate the formation mechanism, climatic effects, and hazard of haze. However, most of these studies focused on the North China at present. Aerosols are generally difficult to characterize uniformly on a global scale due to their large spatiotemporal variability and relatively short lifecycle in the atmosphere (Eck et al., 2010). There is a relative lack of studies of the aerosol optical properties during haze periods under high humidity urban condition (Jin et al., 2019). Therefore, it is important for us to understand aerosol environments in a specific region.

Wuhan, a mega city of Central China, is located in the eastern portion of the Jianghan plain and the Yangtze River middle reaches. It has been facing serious air pollution due to rapid economic development. Automobile exhaust emissions, fossil fuels, and biomass burning produce large quantities of anthropogenic aerosol particles, which, coupled with the high humidity conditions caused by large amounts of water vapor originating from surrounding rivers and lakes, frequently cause haze events during winters (Zhang et al., 2017). In order to enhance understandings of aerosol change in this specific region during winter haze periods, we investigated temporal and spatial variations in aerosols optical properties over Wuhan in the study, based on a CIMEL sun-sky radiometer (CE-318) measurements and an improved Dark Target (DT) method, respectively.

\section{DATA AND METHODS}

\subsection{Study Region and Data}

Wuhan is the capital of Hubei province and one of the important economic and cultural center in Central China. The city has a total area of 8,569 square kilometres, a resident population of 9.08 million, and 166 lakes of different sizes. Figure 1 shows a true colour satellite image of Wuhan with four sub-images to display the real terrain and landcover types with different degrees of urbanization. Compared with the rural area (brick structures and farmlands), the suburban area contains more reinforced concrete buildings which influences underlay surface reflectance and reveals a higher degree of urbanization with different anthropogenic emissions. Our observation station is established on the roof of the State Key Laboratory of Information Engineering in Surveying, Mapping, and Remote Sensing $\left(114^{\circ} 21^{\prime} \mathrm{E}, 30^{\circ} 32^{\prime} \mathrm{N}\right)$ at Wuhan University, influenced mainly by emissions from urban human activities. To study the temporal changes of aerosols during haze, we collected the data of the CE-318 from 2007 to 2016. This instrument is calibrated annually by the China Meteorological Administration Aerosol Remote Sensing Network (Che et al., 2009) to ensure reliability of the data.

The spatial distributions of Aerosol Optical Depth (AOD) were retrieval from original Terra/Aqua MODIS reflectance images with $500 \mathrm{~m}$ resolution. Additional input data for retrieval to calculate cloud mask, gas absorbing correction, and landcover 
type were acquired from MODIS products (including MxD35 for cloud mask, MxD05 for water vapor, and MCD12Q1 for landcover type) and the OMI measurements (ozone). The validation data was from standard DT product released by MODIS (MxD04) and in-situ measurements by the CE-318.

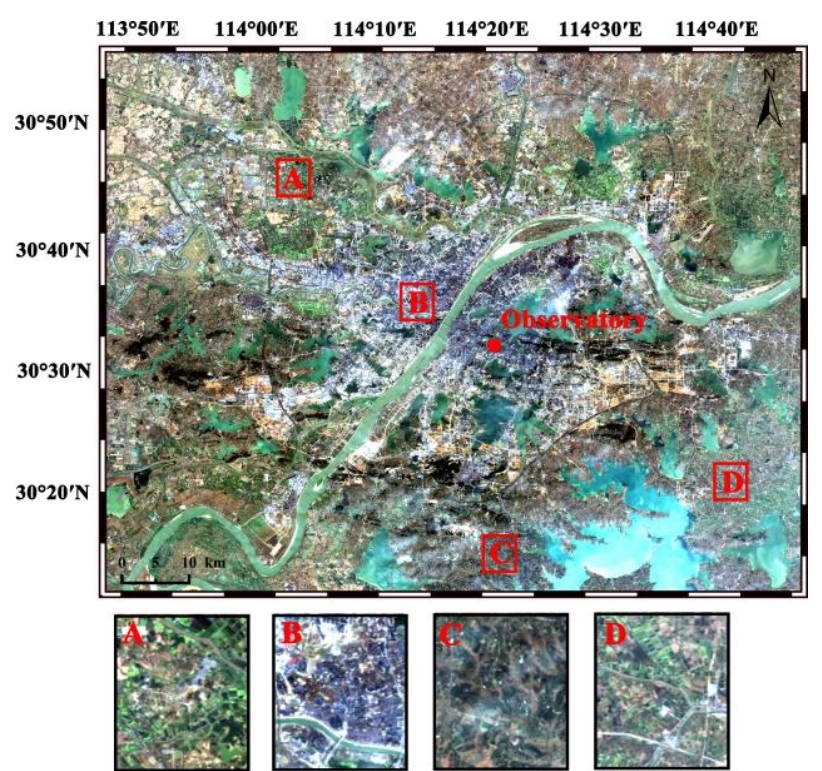

Figure 1. True colour image shows the real terrain of Wuhan obtained by the Landsat- 8 in November 17, 2017. Lakes and rivers in the city release large amount of water vapor and cause a high-humid condition all around year. Sub-images show four main landcover types: (a) rural area and farmlands, (b) urban, (c) natural vegetation, (d) Suburban area.

In addition, visibility and relative humidity $(\mathrm{RH})$ data were used to determine the haze days in Wuhan, obtained from the NOAA's National Climatic Data Center (NCDC). Damp haze, rather than fog, is the main reason for reduced visibility during high-humid days in Wuhan (Ma et al., 2019). Therefore, when the RH is less than $90 \%$, days with the visibility less than $10 \mathrm{~km}$ are considered as haze days and the other are no-haze.

\subsection{Retrieval of Aerosol Characteristics}

The CE-318 is a multi-channel solar spectral scanning radiometer with two tubes automatically measure direct solar radiation and sky diffuse light from 340 to $1020 \mathrm{~nm}$. The AOD is acquired using the ASTPwin software (Cimel Electronique), with uncertainty of $\sim 0.01$ (Eck et al., 1999), while the Angstrom Exponent (AE) is calculated from the negative of the first derivative of the AOD with the associated wavelength on a logarithmic scale (Ångstrom, 1964). Other aerosol optical and microphysical properties, such as Aerosol Size Distribution (ASD), Single Scattering Albedo (SSA), and Asymmetry Factor (AF), are calculated following the method proposed by Dubovik and King (2000). The relative errors of ASD are less than 10\% when the particle radius fell within the range of 0.1 to $0.7 \mu \mathrm{m}$, and the uncertainty of SSA is between 0.03 and 0.07 depending on the aerosol loading and types (Dubovik et al., 2006).

The spatial distributions of AOD were calculated by an improved DT method at $500 \mathrm{~m}$ resolution. The MODIS operational DT method is used to retrieve aerosol's information from passive satellite measurements, which has been widely verified and applied. It defines schemes to estimate surface reflectance and aerosol types, with a aim of separating surface and atmospheric signals more efficiently (Levy et al., 2013). However, the MODIS DT method have relatively low performance in winters of Wuhan due to frequent haze events (Liu et al., 2018). Therefore, to retrieve AOD over Wuhan with more accurate, we improved the DT method based on recalculated aerosol models which are according to the above CE318 observed aerosol characteristics. More details are described in section 3.2.

\section{RESULTS}

\subsection{Variations of Aerosol Characteristics}

Interannual variations of $\mathrm{AOD}$ and $\mathrm{AE}$ during the study periods are shown in Figure 2. The aerosols showed an obvious change with the haze developing. Decadal winter average AOD and AE increased from 0.46 and 1.12 to 0.93 and 1.23 respectively, revealing a large number of fine-mode aerosol particles. Except for heavy haze observed in 2007 with AOD of 1.08, the AOD showed an increasing first and then decreasing trend during haze periods from 2008 to 2016. The maximum AOD appeared in 2011 (1.22), and the minimum value (0.73) was in 2014. In addition, the AE fluctuated within a smaller range around 1.26 during haze periods excluding 2015. The abnormally low value ( 0.95) of AE in 2015 implied relatively large aerosol particles which is most likely due to long-distance dust transport.
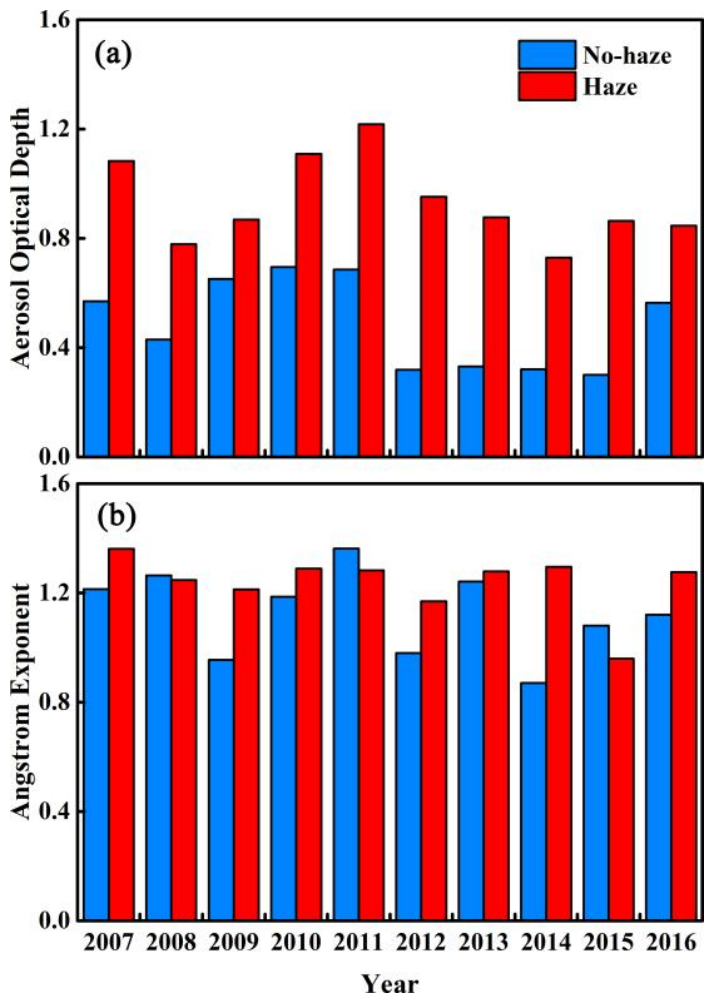

Figure 2. Time series charts of (a) AOD (500 nm) and (b) AE (440-870 nm) in 2007-2016 winters.

For investigating aerosol size changes further, the ASD was calculated and shown in Figure 3. The ASD is a bimodal size distribution dependent on integrative action of fine and coarse mode particles. It is closely related to the variation in aerosol optical properties, such as the $\mathrm{AE}$ and fine-mode fraction (FMF). Under no-haze conditions, the coarse-mode particles were dominant with their peak value of $0.081 \mu \mathrm{m}^{3} / \mu \mathrm{m}^{2}$. However, when the haze events happened, the fine-mode particle showed 
a large increase and their peak value increase from 0.047 to $0.091 \mu \mathrm{m}^{3} / \mu \mathrm{m}^{2}$. In the meantime, the fine-mode peak radius was also found to have increased from 0.148 to $0.194 \mu \mathrm{m}$ which is probably caused by the hygroscopic growth.

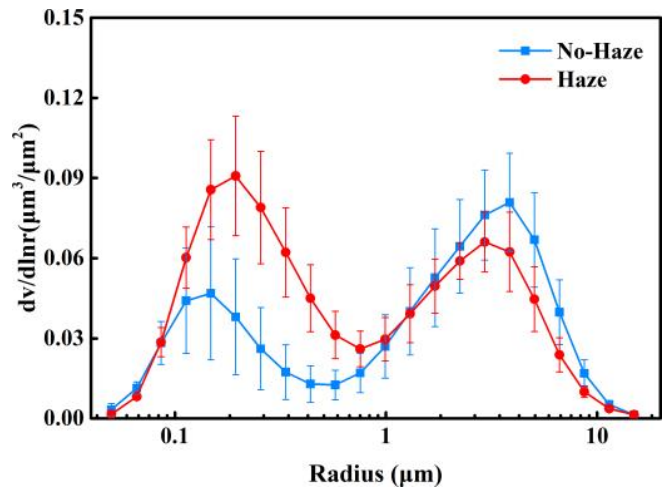

Figure 3. Time series of the aerosol volume size distribution.
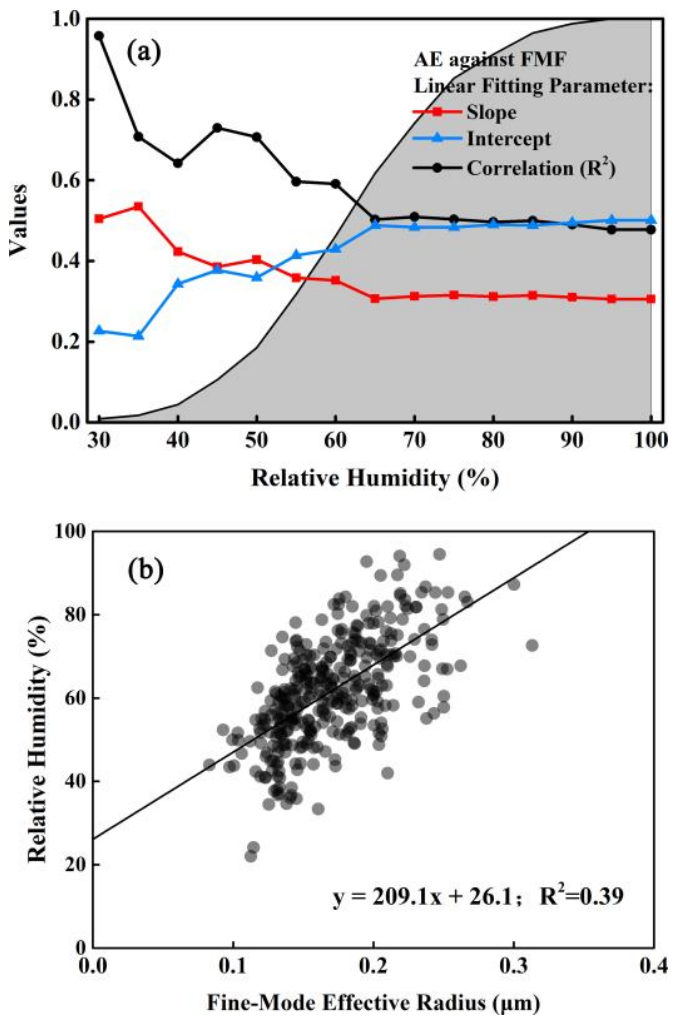

Figure 4. Influence of RH on aerosols. (a) Relationship of FMF $(440 \mathrm{~nm})$ and $\mathrm{AE}(440-870 \mathrm{~nm})$ changes with the RH. Slope, intercept and $\mathrm{R}^{2}$ in the plots are parameters of the linear fitting, representing trends and correlations at different $\mathrm{RH}$ conditions. Shadow is cumulative probability distribution of $\mathrm{RH}$ and it also represents proportion of sample in the total. (b) Dependence of fine-mode effective radius on RH. The black line is linear fitting line.

Influenced by high-humid urban conditions, the aerosol optical and microphysical properties have changed during haze periods. Figure 4 showed the corresponding variations of $\mathrm{AE}, \mathrm{FMF}$, and fine-mode effective radius. The FMF represents the fraction of fine-mode AOD in the total AOD and it generally shows a good positive linear correlation with the AE (Eck et al., 2010). From the Figure 4(a), the $\mathrm{R}^{2}$ showed a decreasing trend with the RH increasing, and the slope and intercept also changed, indicating that the fine relationship of FMF and AE has been destroyed. With the haze developing, the value of FMF will increase as the increase in fine-mode particles. Whereas, the increase in particle size caused by hygroscopic growth as shown in Figure 4(b) will decrease the value of $\mathrm{AE}$ and finally the relationships of the FMF and AE changed.
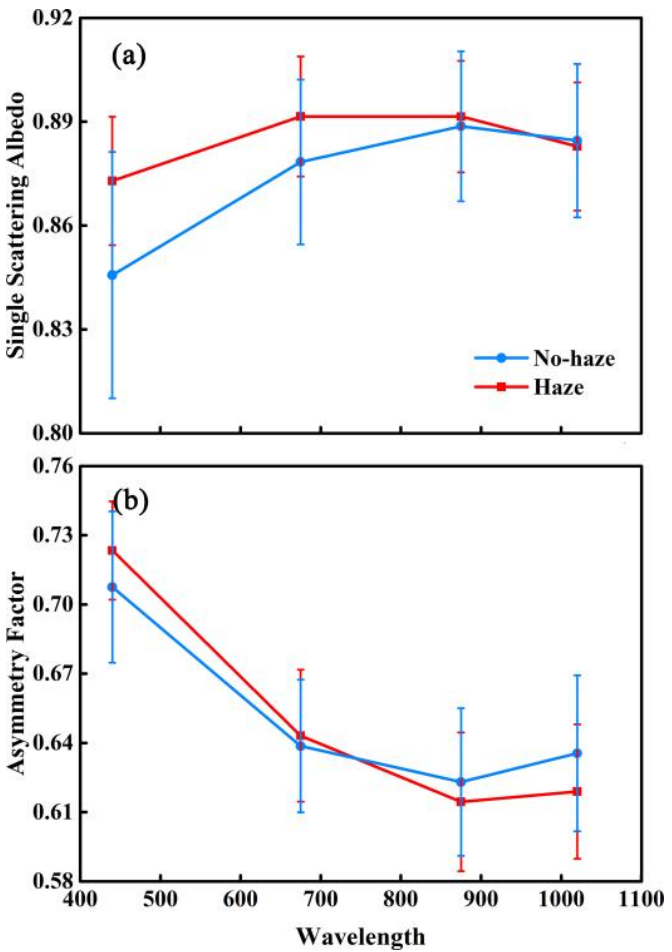

Figure 5. Changes of mean (a) single scattering albedo and (b) asymmetry factor during winter haze periods.

The SSA and ASY were shown in Figure 5 during haze periods representing absorbing and scattering characteristics of aerosol particles. The SSA is the fraction of scattering part in total extinction while the AF represents relationship between forward and backward scattering with a range of $[-1,1]$. Under no-haze conditions, the value of SSA increased from $440 \mathrm{~nm}$ to $870 \mathrm{~nm}$ and then decrease to $1020 \mathrm{~nm}$, and the AF is the opposite. This revealed a fair number of coarse-mode particles, in accordance with the Mie theory (Mie, 1908) that the particle radius is close to the wavelength, the corresponding volume scattering will be close to the maximum. Additionally, mineral dust aerosols also showed strong absorbing in the ultraviolet band (Sokolik and Toon, 1999). When the haze occurred, a larger number of nonabsorbing fine-mode particles emerged and the SSA and AF increased respectively from 0.84 and 0.70 to 0.87 and 0.72 at $440 \mathrm{~nm}$.

\subsection{Aerosol Retrieval and Spatial Distribution}

The spatial distributions of AOD were retrieved from 2016 to 2018 using an DT method with a couple of modified aerosol models which were calculated from the measurements of CE318 from 2012 to 2016 following a K-means clustering approach, to improve retrieval performance over Wuhan during study periods (Jin et al., 2019). The two re-calculated aerosol models depend AOD and the input parameters in cluster analysis were the SSA at $670 \mathrm{~nm}$ and AF at the $440 \mathrm{~nm}$. Their optical and microphysical properties were showed in Table 1, and compared with the continental aerosol model (D'Almeida et 
al., 1991) and the MODIS algorithm DT aerosol models (Levy et al., 2007).

In the Table 1, the SAM (relatively Scattering Aerosol Model) and AAM (relatively Absorbing Aerosol Model) are the two modified aerosol models in our study. The $\mathrm{r}$, $\mathrm{v}$, and $\sigma$ represent aerosol volume modal radius, total volume, and standard deviation, respectively. Subscript $\mathrm{f}$ and $\mathrm{c}$ mean fine-mode and coarse-mode particles. The refractive index is the absorbing and scattering characteristics of aerosol particles at $670 \mathrm{~nm}$. Similar to the mixing of fine and coarse mode in the MODIS DT method (Levy et al., 2007), we retrieved AOD by mixing one of our modified aerosol models (SAM or AAM depending on minimum fitting error) and the continental aerosol model. The continental model can reflect atmospheric background while our models define the changes of aerosol when air pollution occurs over Wuhan.

Table 1. Comparing SAM and AAM with MODIS DT algorithm aerosol models and the continental aerosol model at an aerosol optical depth (AOD) of 0.5

\begin{tabular}{lcccccccc}
\hline & Model & $\mathbf{r f}_{\mathbf{f}}$ & $\mathbf{r}_{\mathbf{c}}$ & $\mathbf{v f}$ & $\mathbf{v}_{\mathbf{c}}$ & $\boldsymbol{\sigma f}_{\mathrm{f}}$ & $\boldsymbol{\sigma}_{\mathbf{c}}$ & Refractive Index \\
\hline \multirow{2}{*}{ Our study } & SAM & 0.159 & 2.188 & 0.072 & 0.114 & 0.494 & 0.631 & $1.495-0.007 \mathrm{i}$ \\
& AAM & 0.144 & 2.210 & 0.074 & 0.113 & 0.482 & 0.644 & $1.501-0.012 \mathrm{i}$ \\
& Developing & 0.155 & 3.269 & 0.096 & 0.092 & 0.442 & 0.778 & $1.430-0.007 \mathrm{i}$ \\
MODIS DT & Smoke & 0.139 & 3.922 & 0.094 & 0.065 & 0.423 & 0.763 & $1.510-0.020 \mathrm{i}$ \\
& Urban-Ind & 0.162 & 3.396 & 0.097 & 0.060 & 0.440 & 0.841 & $1.420-0.006 \mathrm{i}$ \\
& Dust & 0.147 & 2.200 & 0.043 & 0.326 & 0.682 & 0.574 & $1.502-0.002 \mathrm{i}$ \\
& WATE & 0.180 & & 3.050 & & 1.090 & & $1.530-0.006 \mathrm{i}$ \\
Continental & DUST & & 17.600 & & 7.360 & & 1.090 & $1.530-0.008 \mathrm{i}$ \\
& SOOT & 0.050 & & 0.105 & & 0.690 & & $1.750-0.430 \mathrm{i}$ \\
\hline
\end{tabular}

The validation results were shown in Figure 6. Compared with MODIS products, our result showed higher EE\% and N, though the $\mathrm{R}^{2}$ was slightly lower. Due to the lack of Aerosol Robotic Network observations, the MODIS operational DT method used default aerosol model (Developing in the Table 1; moderately absorbing) to calculate AOD over Wuhan. As the imaginary part of the complex refractive index, this model underestimates absorbing of aerosol and causes overestimation of AOD retrieval. Additionally, due to the high humidity over Wuhan, the hygroscopic growth of particles is probably also underestimated in the Developing model at meantime. As a result, our retrievals showed high accuracy and efficiency in winters of Wuhan.

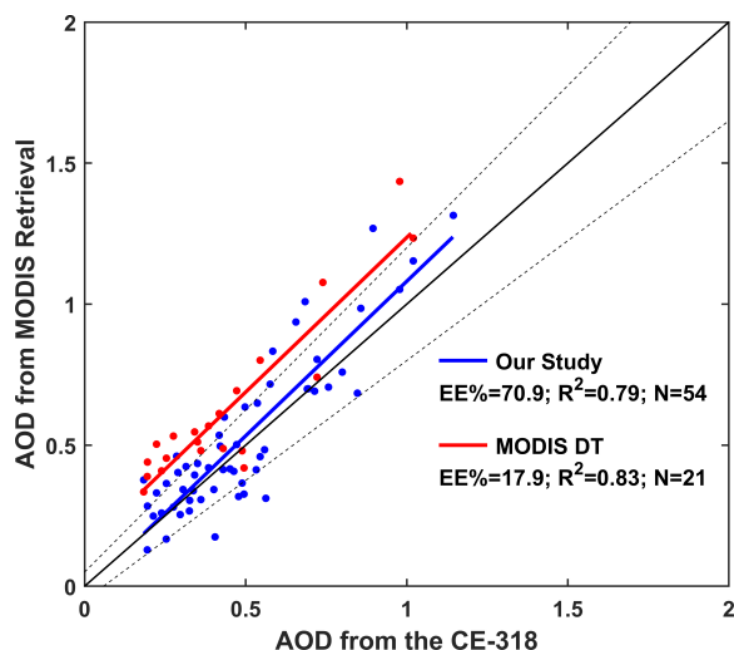

Figure 6. Validations of retrieved AOD of our study (blue) and MODIS $10 \mathrm{~km}$ DT products (red), against with ground-based measurements by CE-318. The EE\% means expect error (\%) and the $\mathrm{N}$ is matching number of retrievals.

Figure 7 showed spatial distributions and changes of aerosol during winter haze periods over Wuhan. Overall, high values of AOD ( 1.0 in haze and $\sim 0.75$ in no-haze) were concentrated in rural and suburban areas rather than city centres in the winters, mainly including the northwest, northeast, southwest, and southeast of the city. This phenomenon was most likely related to the distribution of local emission sources as heavy industry moved to the periphery of the city for alleviating the air pollution. People living in suburbs also tended to have more burning behaviours (biomass and fossil fuels instead of electricity) during winters, which increased the emissions of anthropogenic aerosol particles. Under no-haze conditions, the north and due south of city is relatively clear with AOD almost less than 0.5 . With the haze developing, the gradual decline of increases in aerosols from north to south can be found, which also suggested that the impact of air pollution in North China.

\section{CONCLUSIONS}

A temporal and spatial investigation was done in the study to improve understandings of changes in aerosol during winter haze periods over Wuhan, based on the measurements of sunsky radiometer and an DT method. Aerosol changed significantly during haze periods. Mean AOD and AE increased from 0.46 and 1.12 to 0.93 and 1.23 with the development of haze. The ASD showed that fine-mode particles were predominant under haze conditions with an average peak value of $0.091 \mu \mathrm{m}^{3} / \mu^{2}$. A positive correlation was found between the particle peak radius and relative humidity $\left(\mathrm{R}^{2}=0.39\right)$ during haze periods, showing high hygroscopic growth which also resulted in decreased correlation from 0.89 to 0.49 between $\mathrm{AE}$ and fine mode fraction with the development of haze. An increase in SSA was found during haze from 0.84 to 0.87 at 440 $\mathrm{nm}$, indicating the emergence of numerous fine-mode, nonabsorbent aerosols. Additionally, the SSA increased from 440 $\mathrm{nm}$ to $670 \mathrm{~nm}$ and the decreases from $670 \mathrm{~nm}$ to $1020 \mathrm{~nm}$, while the AF was the opposite. This implied the existence of short-wave absorbing aerosol, such as mineral dust. Overall, the large increase in fine-mode, non-absorbent particles is the fundamental reason causing the haze event over Wuhan. Our recalculated aerosol model showed an improvement to retrieve aerosols over Wuhan. The distributions of AOD showed that high aerosol loading mainly occurs in the rural and suburban areas of Wuhan, and low AOD is always at south of Wuhan where natural vegetation covers mostly. This may be due to the migration of industry to surrounding cities and the burning of 
biomass for warm in winter. In addition, when haze events occurred, the AOD increased significantly $(\sim 0.3)$ in the north of the city, suggesting the impact of pollutants in northern China.
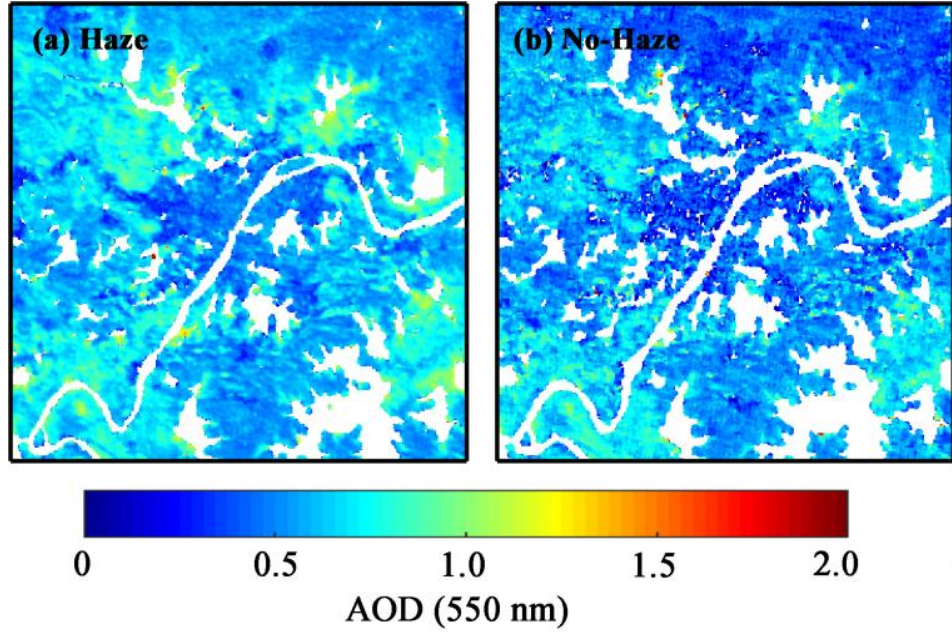
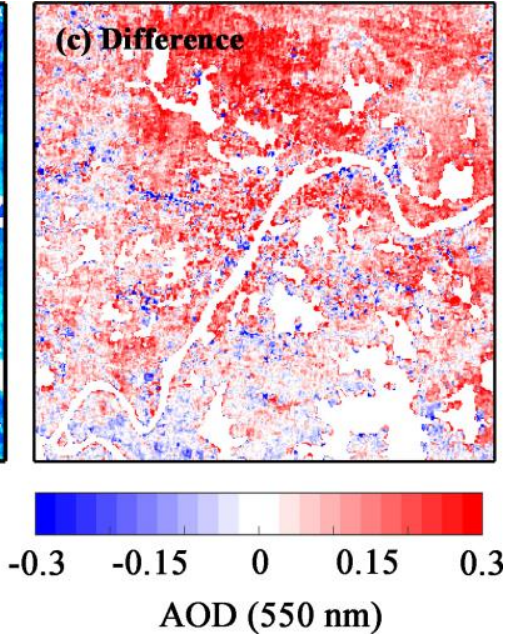

Figure 7. Spatial distributions of average AOD over Wuhan during (a) haze and (b) no-haze conditions. The (c) difference means the haze minus the no-haze.

\section{ACKNOWLEDGEMENTS (OPTIONAL)}

This work was supported by the National Key R\&D Program of China (Grant No. 2018YFB0504500) and the National Natural Science Foundation of China (Grant No. 41875038, No. 41801261, and No. 41905032). We are grateful to the National Climatic Data Center (NCDC) for meteorological parameters and to the MODIS team for satellite imagery and products used in this study.

\section{REFERENCES}

Ångstrom, A.: The Parameter of Atmospheric Turbidity, Tellus, 14, 1964.

Charlson, R. J., Schwartz, S. E., Hales, J. M., Cess, R. D., Coakley, J. A., Hansen, J. E., and Hofmann, D. J.: CLIMATE FORCING BY ANTHROPOGENIC AEROSOLS, Science, 255, 423-430, 10.1126/science.255.5043.423, 1992.

Che, H., Zhang, X., Chen, H., Damiri, B., Goloub, P., Li, Z., Zhang, X., Wei, Y., Zhou, H., and Dong, F.: Instrument calibration and aerosol optical depth validation of the China Aerosol Remote Sensing Network, Journal of Geophysical Research Atmospheres, 114, D03206, 2009.

D'Almeida, G. A., Koepke, P., and Shettle, E. P.: Atmospheric aerosols: Global climatology and radiative characteristics, Journal of Medical Microbiology, 54, 55-61, 1991.

Dubovik, Sinyuk, A., Lapyonok, T., Holben, B. N., Mishchenko, M., Yang, P., Eck, T. F., Volten, H., Munoz, O., and Veihelmann, B.: Application of light scattering by spheroids for accounting for particle non-sphericity in remote sensing of desert dust, Journal of Geophysical Research Atmospheres, 111, 2006.

Dubovik, O., and King, M. D.: A flexible inversion algorithm for retrieval of aerosol optical properties from Sun and sky radiance measurements, Journal of Geophysical Research Atmospheres, 105, 20673-20696, 2000.
Eck, T. F., Holben, B. N., Reid, J. S., Dubovik, O., Smirnov, A., O'Neill, N. T., Slutsker, I., and Kinne, S.: Wavelength dependence of the optical depth of biomass burning, urban, and desert dust aerosols, Journal of Geophysical Research: Atmospheres, 104, 31333-31349, 10.1029/1999jd900923, 1999.

Eck, T. F., Holben, B. N., Sinyuk, A., Pinker, R. T., Goloub, P., Chen, H., Chatenet, B., Li, Z., Singh, R. P., Tripathi, S. N., Reid, J. S., Giles, D. M., Dubovik, O., O'Neill, N. T., Smirnov, A., Wang, P., and Xia, X.: Climatological aspects of the optical properties of fine/coarse mode aerosol mixtures, J. Geophys. Res.-Atmos., 115, 20, 10.1029/2010jd014002, 2010.

Eck, T. F., Holben, B. N., Sinyuk, A., Pinker, R. T., Goloub, P., Chen, H., Chatenet, B., Li, Z., Singh, R. P., Tripathi, S. N., Reid, J. S., Giles, D. M., Dubovik, O., O'Neill, N. T., Smirnov, A., Wang, P., and Xia, X.: Climatological aspects of the optical properties of fine/coarse mode aerosol mixtures, Journal of Geophysical Research, 115, 10.1029/2010jd014002, 2010.

Jin, S., Ma, Y., Zhang, M., Gong, W., Dubovik, O., Liu, B., Shi, Y., and Yang, C.: Retrieval of $500 \mathrm{~m}$ Aerosol Optical Depths from MODIS Measurements over Urban Surfaces under Heavy Aerosol Loading Conditions in Winter, Remote Sensing, 11, 2218, 10.3390/rs11192218, 2019.

Jin, S., Ma, Y., Zhang, M., Gong, W., Lei, L., and Ma, X.: Comparation of aerosol optical properties and associated radiative effects of air pollution events between summer and winter: A case study in January and July 2014 over Wuhan, Central China, Atmospheric Environment, 218, 117004, 10.1016/j.atmosenv.2019.117004, 2019.

Levy, R. C., Remer, L. A., and Dubovik, O.: Global aerosol optical properties and application to Moderate Resolution Imaging Spectroradiometer aerosol retrieval over land, Journal of Geophysical Research Atmospheres, 112, -, 2007.

Levy, R. C., Remer, L. A., Mattoo, S., Vermote, E. F., and Kaufman, Y. J.: Second-generation operational algorithm: Retrieval of aerosol properties over land from inversion of 
Moderate Resolution Imaging Spectroradiometer spectral reflectance, J. Geophys. Res.-Atmos., 112, 10.1029/2006jd007811, 2007.

Levy, R. C., Mattoo, S., Munchak, L. A., Remer, L. A., Sayer, A. M., Patadia, F., and Hsu, N. C.: The Collection 6 MODIS aerosol products over land and ocean, Atmospheric Measurement Techniques, 6, 2989-3034, 10.5194/amt-6-29892013, 2013.

Liu, B., Ma, Y., Gong, W., Zhang, M., and Yang, J.: Study of continuous air pollution in winter over Wuhan based on groundbased and satellite observations, Atmospheric Pollution Research, 9, 156-165, 10.1016/j.apr.2017.08.004, 2018.

Liu, B., Ma, Y., Shi, Y., Jin, S., Jin, Y., and Gong, W.: The characteristics and sources of the aerosols within the nocturnal residual layer over Wuhan, China, Atmospheric Research, 241, 104959, 10.1016/j.atmosres.2020.104959, 2020.

Ma, Y., Zhang, M., Jin, S., Gong, W., Chen, N., Chen, Z., Jin, Y., and Shi, Y.: Long-Term Investigation of Aerosol Optical and Radiative Characteristics in a Typical Megacity of Central China During Winter Haze Periods, Journal of Geophysical Research: Atmospheres, 124, 12093-12106, 10.1029/2019jd030840, 2019.

Mie, G.: Beitrage Zur Optik Truber Medien, Speziell Kolloidaler Metallosungen, Annalen Der Physik, 25, 377, 1908.
Nakajima, T., Yoon, S. C., Ramanathan, V., Shi, G. Y., Takemura, T., Higurashi, A., Takamura, T., Aoki, K., Sohn, B. J., Kim, S. W., Tsuruta, H., Sugimoto, N., Shimizu, A., Tanimoto, H., Sawa, Y., Lin, N. H., Lee, C. T., Goto, D., and Schutgens, N.: Overview of the Atmospheric Brown Cloud East Asian Regional Experiment 2005 and a study of the aerosol direct radiative forcing in east Asia, J. Geophys. Res.-Atmos., 112, 23, 10.1029/2007jd009009, 2007.

Sokolik, I. N., and Toon, O. B.: Incorporation of mineralogic composition into models of the radiative properties of mineral aerosol from UV to IR wavelengths, Journal of Geophysical Research Atmospheres, 104, 9423-9444, 1999.

Tao, M. H., Chen, L. F., Su, L., and Tao, J. H.: Satellite observation of regional haze pollution over the North China Plain, J. Geophys. Res.-Atmos., 117, 16, 10.1029/2012jd017915, 2012.

Zhang, M., Ma, Y., Gong, W., Wang, L., Xia, X., Che, H., Hu, B., and Liu, B.: Aerosol radiative effect in UV, VIS, NIR, and SW spectra under haze and high-humidity urban conditions, Atmospheric Environment, 166, 9-21, 10.1016/j.atmosenv.2017.07.006, 2017.

Zhang, M., Ma, Y., Gong, W., Liu, B., Shi, Y., and Chen, Z.: Aerosol optical properties and radiative effects: Assessment of urban aerosols in central China using 10-year observations, Atmospheric Environment, 182, 275-285, 10.1016/j.atmosenv.2018.03.040, 2018. 